\title{
Studying the Effect of PMG on the Hydrodynamic Characteristics and Stability of PLGA-Vegetable Oil Hybrid Nanoparticles Obtained by Emulsion Solvent Evaporation Method
}

\author{
JANA GHITMAN ${ }^{1}$, RALUCA L. STAN ${ }^{2 *}$ \\ ${ }^{1}$ University Politehnica of Bucharest, Advanced Polymer Materials Group, 1-7 Gh Polizu Str., 011061, Bucharest, Romania \\ ${ }^{2}$ University Politehnica of Bucharest, Faculty of Applied Chemistry and Material Science, 1-5 Gh. Polizu Str., 011061, Bucharest, Romania
}

The main goal of this research study was to understand the role of the vegetable oil in the obtaining process of nanoparticles by emulsion solvent evaporation method, respectively the effect of the vegetable oil upon the final characteristics of hybrid PLGA-pomegranate vegetable oil (PMG) nanoparticles. Colloids with mean diameter around $125.6 \mathrm{~nm}(P L G A-n p)$ and $141.7 \mathrm{~nm}$ (PLGA-PMG-np) were obtained. It was noted that the addition of the vegetable oil has a key role in the primary emulsification process leading to hybrid colloids with improved the uniformity (PdI) and stability of hybrid nanoparticles.

Keywords: colloids, vegetable oil, stability, hydrophilic-lipophilic balance, critical micelle concentration

Nano-sized poly(lactic-co-glycolic) (PLGA) particles represent ones of the most powerful tools used in the field of drug delivery [1]. The increased attention attributed to PLGA based nanoparticles is owed to their remarkable characteristics such as biocompatibility, biodegradability, versatility in formulation [2], good stability and protection of the encapsulated therapeutic agent from premature degradation in the biological environment [3].

Recently a notable interest has focused on hybrid nanoparticles designed from PLGA and different vegetable oil, obtained by emulsion solvent evaporation method [2,4]. Besides safety and effectiveness, the most important particularity of the vegetable oils-mediated synthesis of hybrid nanoparticles is the endowment with different biological activities such as antibacterial [5], anti-inflammatory or anticancer [6]. However, the effect of vegetable oil upon the final hydrodynamic and morphological features of hybrid colloids, particularly the physical phenomenon which take place in the primary emulsification process after the addition of supplementary high lipophilic compound (vegetable oil) have not sufficiently investigated.

The main goal of this research study was to study the effect of the vegetable oil upon the final characteristics of hybrid PLGA-pomegranate vegetable oil (PMG) nanoparticles obtained by emulsion solvent evaporation method. In this context, the main contribution of vegetable oil in the primary emulsification process, respectively in the emulsion formation was thorough explored. The key parameter related to the emulsion stability, hydrophilic-lipophilic balance (HLB), was also determined and compared. The obtained emulsion without/with oil were subjected to stability (zeta potential) and homogeneity studies (DLS) as well as macroscopic and microscopic structure of the emulsions were investigated.

\section{Experimental part}

Materials and methods

Poly (lactic-co-glycolic) acid 50:50, acid terminated with Mol. wt. 40000 - 75000 Da (PLGA), polyvinyl alcohol with Mol. wt. 30000 - 70000 Da, 87 - 90\% hydrolyzed (PVA) dichloromethane (DCM) > 99.9\%, Sorbitan monostearate (Span60, HLB=4.3), Polyoxyethylene sorbitan monostearate (Tween-60, HLB=14.9), Polyethylene-polypropylene glycol (Pluronic F-68, HLB=29), Pomegranate oil (PMG) was supplied by SC Herbavit SRL, Bucharest, Romania. The fatty acid methyl esters (FAME) content of the oil was determined gas chromatography (gas-chromatograph Agilent Technologies, 7890 A, Wilmington, DE, USA) and ${ }^{1} \mathrm{H}-\mathrm{NMR}$ spectroscopy (Bruker Avance DRX 400 spectrometer, operating at 9.4 Tesla, corresponding to the resonance frequency of $400.13 \mathrm{MHz}$ for the ${ }^{1} \mathrm{H}$ nucleus) [7]. The obtained results are presented in table 1 , respectively figure 1 .

\footnotetext{
*email: rl_stan2000@yahoo.com
} 
Table 1

THE CONTENT IN FATTY ACIDS METHYL ESTERS

OF PMG DETERMINED BY GC

\begin{tabular}{|l|l|}
\hline Fatty acid & Concentration $(\%)$ \\
\hline Palmitic acid (C16:0) & $3.53 \pm 0.057$ \\
\hline Stearic acid (C18:0) & $1.57 \pm 0.021$ \\
\hline Oleic acid (C18:1) & $5.62 \pm 0.041$ \\
\hline Linoleic acid (C18:2) & $6.11 \pm 0.084$ \\
\hline Punicic acid (C18:3) & $75.11 \pm 0.017$ \\
\hline Cis-11,14-eicosadienoic acid (C20:2) & $8.04 \pm 0.065$ \\
\hline
\end{tabular}

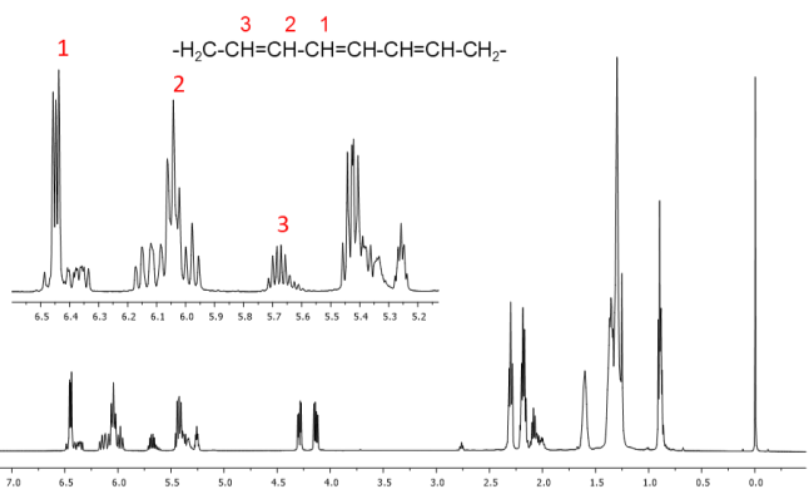

Fig.1. The ${ }^{1} \mathrm{H}-\mathrm{RMN}$ spectrum of transesterified oil

Through ${ }^{1} \mathrm{H}-\mathrm{RMN}$ technique was determined the FAME oil composition and also was identified punicic acid (PA), one of the most important active compounds from conjugated linolenic acids isomers presented in the pomegranate seeds oil composition. In the ${ }^{1} \mathrm{H}-\mathrm{RMN}$ spectrum the PA was determined by identifying the chemical shifts of olefinic protons in the region 5.0-7.0 ppm from acid's chemical structure [8].

\section{Nanoparticles preparation}

Nanoparticles based on PLGA-np or hybrid PLGA-PMG-np were obtained by emulsion solvent evaporation method [9]. PLGA-PMG nanoparticles were obtained by dissolving the polymer and oil (PLGA/PMG ratio 1/1) in $4 \mathrm{~mL}$ DCM (organic phase), which subsequently was slowly added drop-wise to $20 \mathrm{~mL}$ aqueous solution of $2 \% \mathrm{w} / \mathrm{v}$ PVA under constant stirring. The mixture was homogenized through sonication (Vibra-Cell CVX 130, $20 \mathrm{kHz}, 220 \mathrm{~V}$, USA) for $10 \mathrm{~min}$ in an ice bath, afterward was subjected to stirring for $2 \mathrm{~h}$ to evaporate the organic solvent. Then the suspension was centrifuged at 8000 rpm for $30 \mathrm{~min}$ and washed three times using ultra-pure water to remove the residual PVA and PMG. PLGA nanoparticles were obtained succeeding similar steps, except the oil addition.

\section{Size distribution, zeta potential and morphology}

Mean diameter, polydispersity index (PdI) and zeta potential (PZ) of all obtained nanoparticles were determined by Dynamic Light Scattering (Malvern Zeta Sizer ZEN 3600, Worcestershire, UK, DLS). The samples were diluted in deionized water and 12 successive cycles were run at $25^{\circ} \mathrm{C}$, all the measurements were done in triplicate. The morphology of nanoparticles was studied by Scanning Electron Microscopy (SEM, Quanta Inspect F50).

\section{Determination of Critical Micelle Concentration (CMC) of stabilizer agent (PVA)}

CMC of PVA was established using tensiometry method, Hun-Manson and Lw.-Waters principle (Tensiometer, Sigma 702), by determining the surface tension of a series of aqueous stabilizer solutions prepared at different concentration in the range of 0 to $20 \mathrm{mg} / \mathrm{mL}$ PVA. Then, the graph of surface tension as function of c (PVA) was constructed and CMC of PVA was determined. 
A series of emulsion consisting from PLGA-DCM/Water and PLGA-PMG-DCM/Water were made according to the nanoparticles preparation method. The HLB value was varied between 10 and 22, according to table 4 and 5 . The concentration of stabilizer system (Span-60, Tween-60, Pluronic F-68) from the aqueous phase was maintained 2\% and its HLB value was calculated according to the formula (1):

Where: A, B -selected non-ionic stabilizers.

$$
H L B=x A+(1-x) B
$$

The stability of obtained emulsions was appreciated based on zeta potential (PZ) and size distribution measurements as well as macroscopic and microscopic results.

\section{Results and discussions}

The hydrodynamic characteristics of obtained nanoparticles are presented in table 2.

Table 2

HYDRODYNAMIC CHARACTERISTICS AND STABILITY OF ALL NANOPARTICLES
\begin{tabular}{|l|l|l|l|}
\hline Sample & $\mathbf{d}(\mathbf{n m})$ & PdI & PZ $(\mathbf{m V})$ \\
\hline PLGA-np & $125.6 \pm 0.98$ & $0.21 \pm 0.05$ & $-10.30 \pm 0.15$ \\
\hline PLGA-PMG-np & $141.70 \pm 1.40$ & $0.13 \pm 0.01$ & $-18.90 \pm 0.49$ \\
\hline
\end{tabular}

PLGA-np with a mean size around $125 \mathrm{~nm}$ and moderate stability were obtained. The medium zeta negative potential was attributed to the end carboxylic groups from PLGA structure [10]. The addition of 1/1 wt. PMG with respect to the polymeric matrix increased the dimension of HPON-NP with 10\% while the uniformity and stability of PLGA-PMG-np was improved with $\sim 60 \%$, respectively $\sim 55 \%$. It can be noted that the oil addition is one of the key parameter with a great influence on the mean size, PdI and stability of colloids.

To further confirm the DLS results and to assess the morphological features of PLGA-np and hybrid PLGA-PMG-np, the colloids were subjected to SEM investigations. Generally, both images highlighted the formation of homogenous slightly agglomerate population with regular spherical structures and mean diameter $\sim 100 \mathrm{~nm}$ in the case of PLGA-np, respectively $\sim 120 \mathrm{~nm}$ where PLGA-PMG-np were studied, in correlation with DLS analysis. It can be also observed the well-defined smooth surface of PLGA-PNG-np comparing with the surface of PLGA-np which presented some irregularities (figure 2).

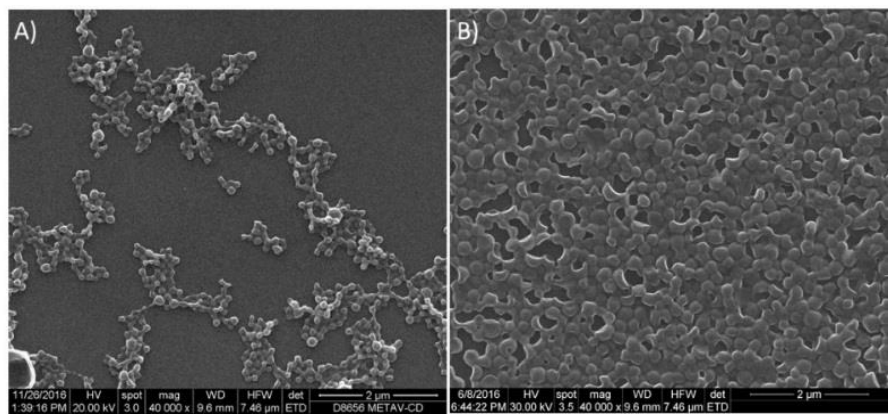

Fig. 2 SEM images of A) PLGA nanoparticles,

B) hybrid PLGA-PMG nanoparticles

This effect was also attributed to the oil's presence in the primary emulsification process which led to the formation of a more stable and uniform emulsion (PLGA-PMG-np).

\section{CMC and emulsion (PLGA-DCM/Water or PLGA-PMG-DCM/Water) stabilizing ability of PVA}

One of the most critical factor in obtaining a stable and uniform emulsion is the critical micelle concentration of stabilizer agent. Before reaching the CMC, the surface tension changes (decreased) strongly with the increase of stabilizer agent concentration while above $\mathrm{CMC}$, stabilizer agent forms micelles and all additional stabilizer added to the system go to micelles and the surface tension changes are insignificant $[11,12]$. The values of surface tension of all analyzed samples determined using two principles are presented in table 3. 
Table 3

THE SURFACE TENSION OF ALL ANALYZED SAMPLES

\begin{tabular}{|l|l|l|l|}
\hline No. & $\mathbf{c}(\mathbf{P V A}) \mathbf{m g} / \mathbf{m L}$ & $\gamma(\mathbf{m N} / \mathbf{m})$ Hun-Manson & $\gamma(\mathbf{m N} / \mathbf{m}) \mathbf{L w . - W a t e r s}$ \\
\hline 1 & 0 & $61.55 \pm 0.2$ & $61.20 \pm 0.02$ \\
\hline 2 & 0.01 & $60.85 \pm 0.16$ & $60.45 \pm 0.21$ \\
\hline 3 & 0.1 & $54.22 \pm 0.29$ & $53.95 \pm 0.22$ \\
\hline 4 & 0.5 & $50.92 \pm 0.23$ & $50.69 \pm 0.23$ \\
\hline 5 & 1 & $48.85 \pm 0.19$ & $48.64 \pm 0.19$ \\
\hline 6 & 3 & $45.81 \pm 0.17$ & $45.65 \pm 0.16$ \\
\hline 7 & 5 & $44.81 \pm 0.16$ & $44.66 \pm 0.15$ \\
\hline 8 & 8 & $43.93 \pm 0.12$ & $43.80 \pm 0.11$ \\
\hline 9 & 10 & $43.61 \pm 0.08$ & $43.49 \pm 0.08$ \\
\hline 10 & 15 & $43.33 \pm 0.08$ & $43.21 \pm 0.08$ \\
\hline 11 & 20 & $42.99 \pm 0.07$ & $42.87 \pm 0.07$ \\
\hline
\end{tabular}

In figure 3 is highlighted the variation of surface tension of PVA solutions as a function of PVA concentration and the estimated CMC value of PVA. The surface tension gradually decreased with the increase of PVA concentration until the system reach the CMC point, above which the surface tension remained constant. The CMC value obtained for PVA was $0.3 \mathrm{mg} / \mathrm{mL}$, in agreement with reported literature data $(\mathrm{CMC}(\mathrm{PVA})=0.3-0.8 \mathrm{mg} / \mathrm{mL})[13,14]$.

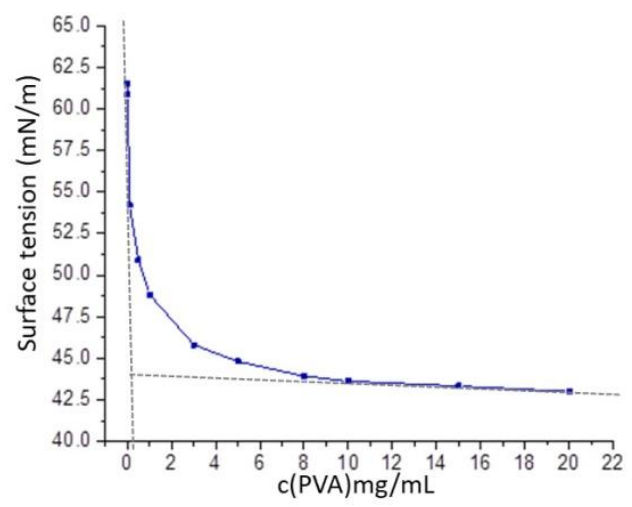

Fig. 3. Surface tension of PVA solution as a function of stabilizer concentration

In nonionic stabilizer system particles are stabilized by steric hindrance and a good stability of emulsion is obtained when there is a sufficient amount of stabilizer molecules in the system (the concentration of PVA used in the preparation step of nanoparticles was $20 \mathrm{mg} / \mathrm{mL}$, which is much higher than the CMC value of PVA).

\section{Determination of the required HLB of PLGA-DCM/Water and PLGA-PMG-DCM/Water}

Another parameter of highest importance in the development of a stable and uniform emulsion is the evaluation of the required hydrophilic lipophilic balance (HLB) of the system. In this system each stabilizer was a numerical HLB value attributed, representing the hydrophilic-lipophilic tendency of the stabilizer [15]. Hydrophilic surfactants possess high HLB value while lipophilic stabilizers have the HLB value less than 6. The optimal surfactant for a certain emulsion should possesses the HLB value as close to the required HLB value of the emulsion; this is the main criterion in selecting the optimal stabilizer which will give an emulsion with good stability. PVA is a hydrophilic surfactant with HLB $=18$ and very good solubility in aqueous phase [16]. Thus, the determination of HLB requirement of PLGA-DCM/Water and PLGAPMG-DCM/Water systems is a useful starting point in the studying the effect of the oil from the emulsion composition in primary emulsification process. To achieve this goal a series of PLGA-DCM/Water and PLGA-PMG-DCM/Water emulsions with different HLB values were prepared and subjected to PZ analysis to determine the systems with optimal stability. The results obtained for all tested heterogeneous systems without/with oil, expressed as zeta potential, are presented in tables 4,5 and figure 4 . 
Table 4

THE STABILITY OF PLGA-DCM/WATER EMULSIONS AT DIFFERENT HLB VALUES

\begin{tabular}{|c|c|c|c|c|c|c|c|c|}
\hline \multirow{2}{*}{ No. } & \multirow{2}{*}{$\begin{array}{l}\text { HLB } \\
\text { value }\end{array}$} & \multirow{2}{*}{$\begin{array}{c}\mathrm{m} \text { (PLGA) } \\
\mathrm{mg}\end{array}$} & \multirow{2}{*}{$\begin{array}{c}\mathrm{V}(\mathrm{DCM}) \\
\mathrm{mL}\end{array}$} & \multirow{2}{*}{$\begin{array}{c}\mathrm{V}\left(\mathrm{H}_{2} \mathrm{O}\right) \\
\mathrm{mL}\end{array}$} & \multicolumn{3}{|c|}{$2 \%-10 \mathrm{~mL}$} & \multirow{2}{*}{$\mathrm{PZ}(\mathrm{mV})$} \\
\hline & & & & & $\begin{array}{c}\% \\
(\text { Span-60) }\end{array}$ & $\begin{array}{c}\% \\
\text { (Tween-60) }\end{array}$ & $\begin{array}{r}\% \\
(\mathrm{P}-68)\end{array}$ & \\
\hline 1 & 10 & 12 & 2 & 10 & 46.22 & 53.78 & - & $-28.1 \pm 0.2$ \\
\hline 2 & 12 & 12 & 2 & 10 & 27.35 & 72.65 & - & $-24.8 \pm 0.3$ \\
\hline 3 & 13 & 12 & 2 & 10 & 17.92 & 82.08 & - & $-22.2 \pm 0.2$ \\
\hline 4 & 14 & 12 & 2 & 10 & 8.49 & 91.51 & - & $-23.4 \pm 1.2$ \\
\hline 5 & 14.9 & 12 & 2 & 10 & - & 100 & - & $-23.6 \pm 1.0$ \\
\hline 6 & 16 & 12 & 2 & 10 & - & 92.10 & 7.90 & $-21.7 \pm 0.4$ \\
\hline 7 & 17 & 12 & 2 & 10 & - & 85.10 & 14.90 & $-21.3 \pm 0.8$ \\
\hline 8 & 18 & 12 & 2 & 10 & - & 78.00 & 22.00 & $-19.5 \pm 0.4$ \\
\hline 9 & 19 & 12 & 2 & 10 & - & 70.92 & 29.08 & $-22.3 \pm 0.5$ \\
\hline 10 & 20 & 12 & 2 & 10 & - & 63.82 & 36.18 & $-22.3 \pm 0.6$ \\
\hline 11 & 21 & 12 & 2 & 10 & - & 56.73 & 43.27 & $-23.7 \pm 0.4$ \\
\hline 12 & 22 & 12 & 2 & 10 & - & 49.64 & 50.36 & $-23.5 \pm 0.4$ \\
\hline
\end{tabular}

Table 5

THE STABILITY OF PLGA-PMG DCM/WATER EMULSIONS AT DIFFERENT HLB VALUES

\begin{tabular}{|c|c|c|c|c|c|c|c|c|c|}
\hline \multirow{2}{*}{ No. } & \multirow{2}{*}{$\begin{array}{l}\text { HLB } \\
\text { value }\end{array}$} & \multirow{2}{*}{$\mathrm{m}(\mathrm{PLGA}) \mathrm{mg}$} & \multirow{2}{*}{$\begin{array}{c}\mathrm{m}(\mathrm{PMG}) \\
\mathrm{mg}\end{array}$} & \multirow{2}{*}{$\begin{array}{c}\mathrm{V}(\mathrm{DCM}) \\
\mathrm{mL}\end{array}$} & \multirow{2}{*}{$\begin{array}{c}\mathrm{V}\left(\mathrm{H}_{2} \mathrm{O}\right) \\
\mathrm{mL}\end{array}$} & \multicolumn{3}{|c|}{$2 \%-10 \mathrm{~mL}$} & \multirow{2}{*}{$\mathrm{PZ}(\mathrm{mV})$} \\
\hline & & & & & & $\begin{array}{c}\% \\
\text { (Span-60) }\end{array}$ & $\begin{array}{c}\% \\
\text { (Tween-60) }\end{array}$ & $\begin{array}{c}\% \\
(\mathrm{P}-68)\end{array}$ & \\
\hline 1 & 10 & 12 & 12 & 2 & 10 & 46.22 & 53.78 & - & $\begin{array}{c}- \\
15.1 \pm 0.1\end{array}$ \\
\hline 2 & 12 & 12 & 12 & 2 & 10 & 27.35 & 72.65 & - & $\begin{array}{c}- \\
17.8 \pm 0.3 \\
\end{array}$ \\
\hline 3 & 13 & 12 & 12 & 2 & 10 & 17.92 & 82.08 & - & $\begin{array}{c}- \\
19.2 \pm 0.4\end{array}$ \\
\hline 4 & 14 & 12 & 12 & 2 & 10 & 8.49 & 91.51 & - & $\begin{array}{c}- \\
18.4 \pm 1.1 \\
\end{array}$ \\
\hline 5 & 14.9 & 12 & 12 & 2 & 10 & - & 100 & - & $\begin{array}{c}- \\
18.6 \pm 0.7\end{array}$ \\
\hline 6 & 16 & 12 & 12 & 2 & 10 & - & 92.10 & 7.90 & $\begin{array}{c}- \\
18.9 \pm 0.3 \\
\end{array}$ \\
\hline 7 & 17 & 12 & 12 & 2 & 10 & - & 85.10 & 14.90 & $\begin{array}{c}- \\
18.9 \pm 0.8\end{array}$ \\
\hline 8 & 18 & 12 & 12 & 2 & 10 & - & 78.00 & 22.00 & $\begin{array}{c}- \\
20.9 \pm 0.6\end{array}$ \\
\hline 9 & 19 & 12 & 12 & 2 & 10 & - & 70.92 & 29.08 & $\begin{array}{c}- \\
20.2 \pm 0.4 \\
\end{array}$ \\
\hline 10 & 20 & 12 & 12 & 2 & 10 & - & 63.82 & 36.18 & $\begin{array}{c}- \\
22.3 \pm 0.7\end{array}$ \\
\hline 11 & 21 & 12 & 12 & 2 & 10 & - & 56.73 & 43.27 & $\begin{array}{c}- \\
28.0 \pm 0.3 \\
\end{array}$ \\
\hline 12 & 22 & 12 & 12 & 2 & 10 & - & 49.64 & 50.36 & $\begin{array}{c}- \\
24.1 \pm 0.8\end{array}$ \\
\hline
\end{tabular}



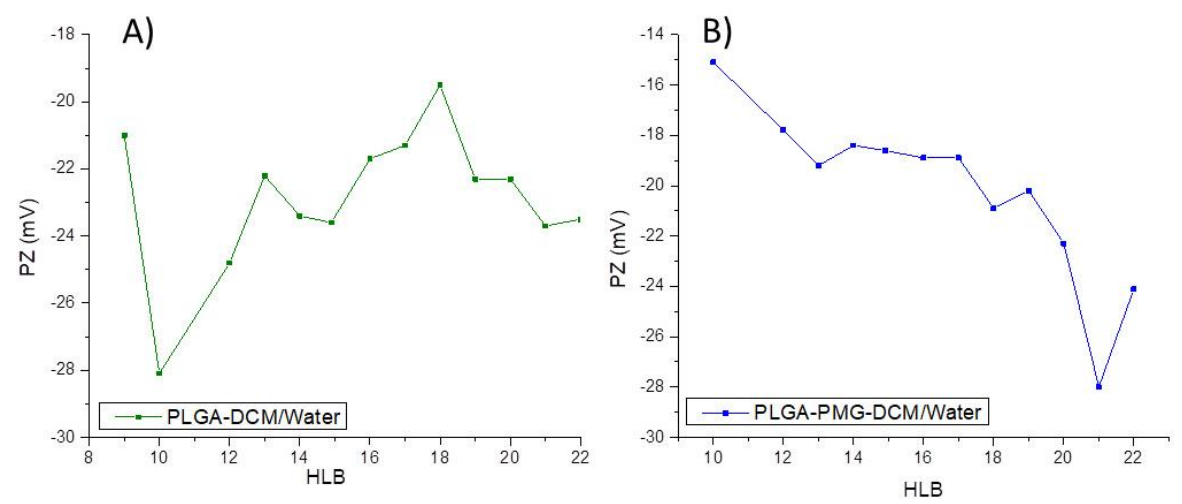

Fig. 4. The zeta potential values determined for A) PLGA-DCM/Water and

B) PLGA-PMG-DCM/Water emulsions at different HLB values

As it can be observed from tables 4 and figure 4, A the highest stability of PLGA-DCM/Water emulsion was obtained at $\mathrm{HLB}=10(\mathrm{PZ}=-28.1 \mathrm{mV})$. In the case of PLGA-PMG-DCM/Water, the results presented in table 5 and figure 4, B revealed the formation of an emulsion with good stability at HLB $=21(\mathrm{PZ}=-28.0 \mathrm{mV})$. The required HLB value for obtaining a good, uniform and stable PLGA-DCM/Water emulsion is 10, the oil addition shifted the hydrophilic-lipophilic balance of the system to high value (HLB $=21)$. This increase is attributed to the addition of the vegetable oil which being a high lipophilic compound increased the required HLB value of the PLGA-PMG-DCM/Water system. In this way to equilibrate the hydrophilic-lipophilic balance of the emulsion it will be necessary a stabilizer agent with high HLB.

As was mentioned, the HLB value of PVA was 18, the calculated HLB value required for PLGA-DCM/Water was 10, respectively 21 for PLGA-PMG-DCM/Water system. The HLB value provided by stabilizer agent is more appropriate to the required HLB for PLGA-PMG-DCM/Water than for PLGA- DCM/Water, emulsion without oil. Therefore, the oil addition acts as a HLB moderator in the primary emulsification process, by increasing the HLB requirement of the system and forming a more stable and uniform emulsion, respectively PLGA-PMG-np with improved hydrodynamic, morphological characteristics and high stability as compared to PLGA-np.

Further, in support to the obtained zeta potential results and to study more detailed the behavior of emulsions, the systems without/with oil at HLB values 10 and 21 (the systems registered highest stability) were subjected to size distribution examinations, the results are presented in figure 5.
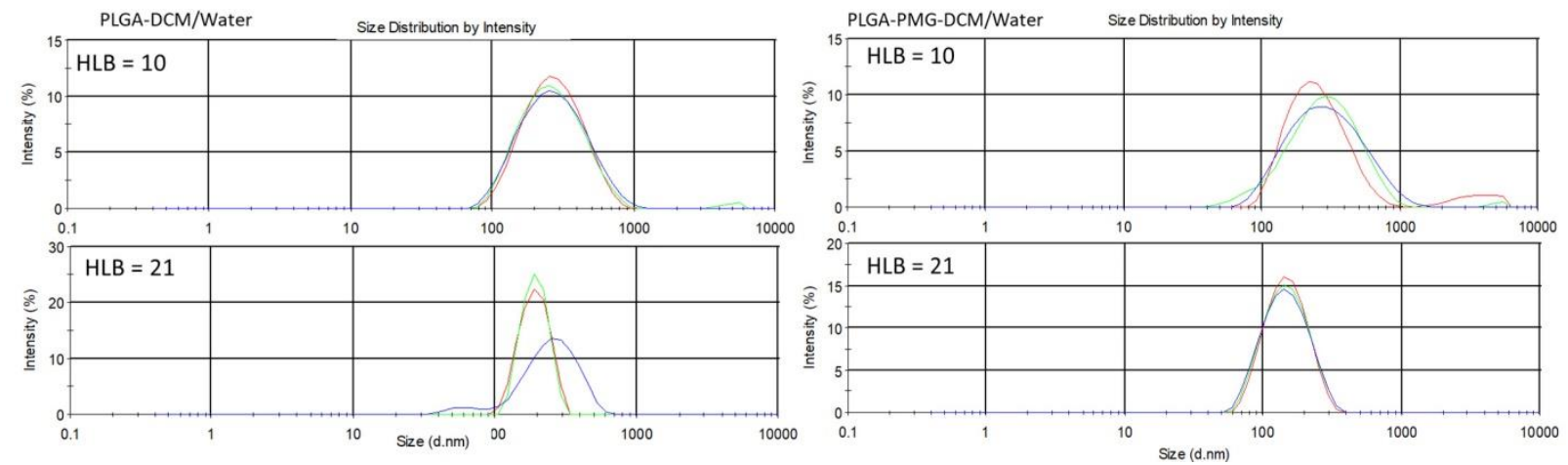

Fig. 5. Size distribution by intensity of PLGA-DCM/Water and PLGA-PMG-DCM/Water emulsions at two HLB values

As was expected, the size distribution of PLGA-DCM/Water colloids revealed the formation of a narrowed, monodisperse, uniform and homogenous population at $\mathrm{HLB}=10$, while at HLB $=21$ a polydisperse, heterogeneous and multimodal distributed population was formed. In the case of emulsion with oil (PLGA-PMG-DCM/Water) narrowed monodisperse and uniform population was formed at HLB $=21$, while at low HLB value, the graph highlighted the presence of colloids with multimodal distribution. The DLS results corroborate with stability analyses.

Macroscopic and Microscopic characterization

Macroscopic observation were carried out to find any kind of changes in the emulsion's structure such as creaming, flocculation or coalescence (phase separation). The samples were subjected to centrifugation at $3500 \mathrm{rpm}$ for 15 min [17] and the macroscopic investigations of samples were made after 5 days storage at room temperature. The evolution of analyzed PLGA-DCM/Water and PLGA-PMG-DCM/Water emulsions is presented in figure 6. 


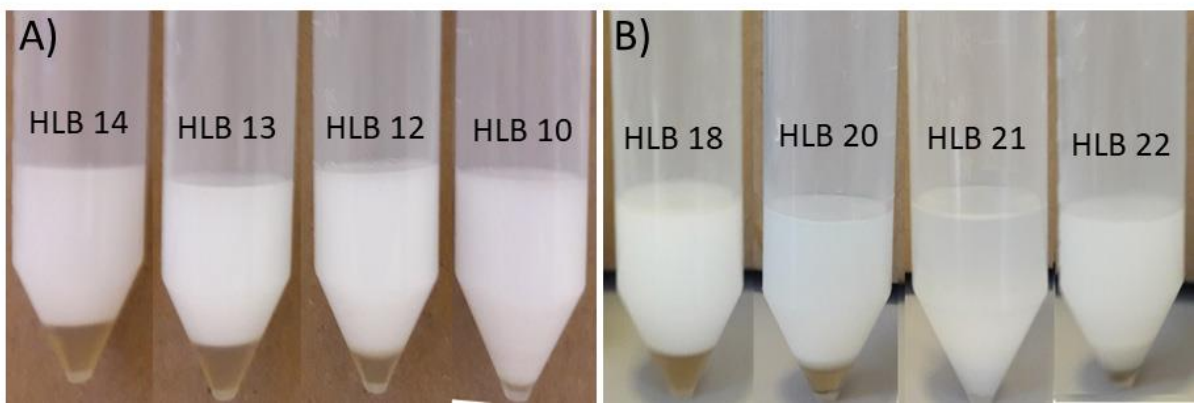

Fig. 6. Macroscopic investigation of A) PLGA-DCM/Water and B) PLGA-PMG-DCM/Water emulsions at different HLB values

After 5 days storage, regardless the type of $\mathrm{O} / \mathrm{W}$ emulsions a distinct and clear line appeared between the separated phases in almost all tested samples, except the PLGA-DCM/Water emulsion at HLB $=10$ and PLGA-PMG-DCM/Water emulsion at HLB $=21$. These samples presented highest stability; a single dispersed phase was maintained after the centrifugation cycle, with slight tendency of phase separation in the case of emulsion without oil.

Then, macroscopically stable or instable forms were submitted to microscopic analysis performed with polarized light view microscope (Nikon). As representative images the PLGA-DCM/Water emulsion at HLB 10 and 21 were selected (figure 7, A, B).
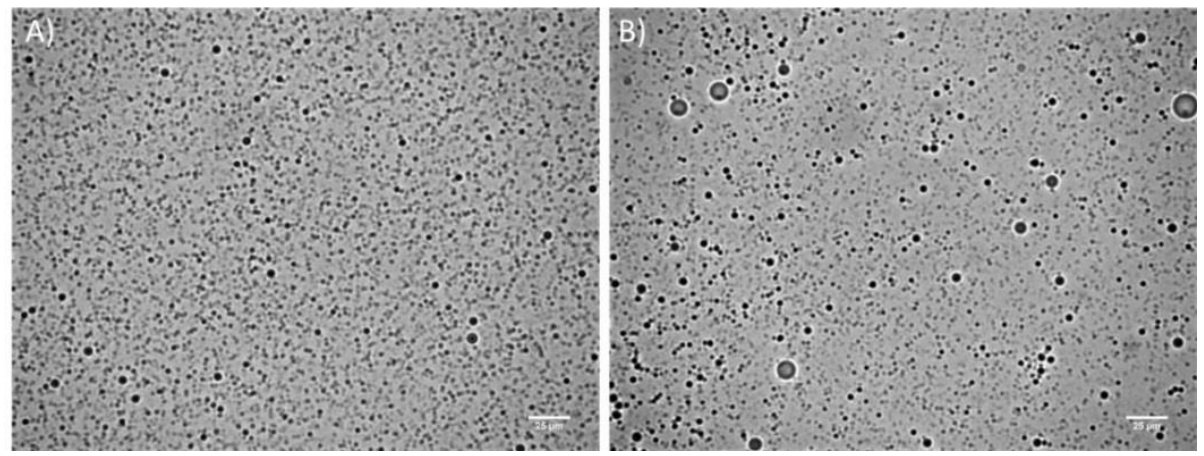

Fig. 7. Microscopic investigation of PLGA-DCM/Water emulsion at A) HLB $=10$; B) HLB = 21

As seen from microscopic images, at HLB $=10$ the PLGA-DCM/Water emulsion was homogeneous with colloids that presented the mead diameter roughly the same (figure 7, A). At the same time the high HLB value lead to colloidal formulation with polydisperse and heterogenous microstructure.

\section{Conclusions}

In this research study the effect of the vegetable oil in designing hybrid nanoparticles by emulsion solvent evaporation method with optimal hydrodynamic and morphological features was investigated. PLGA-np with mean diameter around $120 \mathrm{~nm}$ and medium stability were obtained, while the addition of vegetable oil led to PLGA-PMG-np with slight increased diameter $(141.7 \mathrm{~nm})$ and significantly improved stability. The vegetable oil has a key role in the primary emulsification process, acting as an HLB moderator, by increasing the required HLB value of the hybrid emulsion to HLB value provided by stabilizer agent. The zeta potential and DLS results suggested the formation of a uniform and stable PLGA-DCM/Water emulsion at HLB $=10$, while the hybrid PLGA-PMG-DCM/Water homogeneous emulsion was formed at HLB $=21$. Moreover, the macroscopic and microscopic corroborated the stability results.

This study could represent an important starting point in studying more comprehensive the physical phenomenon which take place in the presence of a high lipophilic compound.

Acknowledgement: The work has been funded by the Operational Programme Human Capital of the Ministry of European Funds through the Financial Agreement 51668/09.07.2019, SMIS code 124705.

\section{References}

1. DANHIER F., ANSORENA E., SILVA J. M., COCO R., LE BRETON A., PRÉAT V. PLGA-based nanoparticles: an overview of biomedical applications. Journal of controlled release, 161, 2012, p. 505-522.

2. ACHARYA S., SAHOO S. K. PLGA nanoparticles containing various anticancer agents and tumour delivery by EPR effect. Advanced drug delivery reviews, 63, 2011, p.170-183. 
3. BALA I., HARIHARAN S., KUMAR M. R. PLGA nanoparticles in drug delivery: the state of the art. Critical Reviews ${ }^{\mathrm{TM}}$ in Therapeutic Drug Carrier Systems, 21, 2004.

4. ASTETE C. E., SABLIOV C. M. Synthesis and characterization of PLGA nanoparticles. Journal of Biomaterials Science, Polymer Edition, 17, 2006, p.247-289.

5. VALERO M., SALMERON M. C. Antibacterial activity of 11 essential oils against Bacillus cereus in tyndallized carrot broth. International journal of food microbiology, 85, 2003, p.73-81.

6. BALASUBRAMANIAN K., RAGUNATHAN R. Study of antioxidant and anticancer activity of natural sources. J Nat Prod Plant Resour, 2, 2012, p.192-197.

7. CHIRA, N. A., TODASCA, M. C., NICOLESCU, A., ROSU, A., NICOLAE, M., ROSCA, S. I. Evaluation of the computational methods for determining vegetable oils composition using 1H-NMR spectroscopy, Rev. Chim. (Bucharest), 62, no.1, 2011, p.42-46.

8. CAO Y., WANG L., HE M., ZHANG Y., WANG H. Nanodispersions of monoglycerides of punicic acid: a potential nutrient precursor with higher oxidative stability and cytotoxicity. RSC Advances, 4, 2014, p.43392-43398.

9. GHITMAN J., STAN R., IOVU H. Experimental contributions in the synthesis of PLGA nanoparticles with excellent properties for drug delivery: Investigation of key parameters. UPB Sci. Bull. Ser. B, 79, 2017, p.101-112.

10. MANCHANDA R., FERNANDEZ-FERNANDEZ A., NAGESETTI A., MCGORON A. J. Preparation and characterization of a polymeric (PLGA) nanoparticulate drug delivery system with simultaneous incorporation of chemotherapeutic and thermo-optical agents. Colloids and Surfaces B: Biointerfaces, 75, 2010, p. 260-267.

11. CHAKRABORTY T., CHAKRABORTY I., GHOSH S. The methods of determination of critical micellar concentrations of the amphiphilic systems in aqueous medium. Arabian Journal of Chemistry, 4, 2011, p.265-270.

12. PATIST A., BHAGWAT S. S., PENFIELD K. W., AIKENS P., SHAH D. O. On the measurement of critical micelle concentrations of pure and technical- grade nonionic surfactants. Journal of Surfactants and Detergents, 3, 2000, p. 53-58.

13. KWON H. Y., LEE J. Y., CHOI S. W., JANG Y., KIM J. H. Preparation of PLGA nanoparticles containing estrogen by emulsification-diffusion method. Colloids and Surfaces A: Physicochemical and Engineering Aspects, 182, 2001, p.123-130.

14. XU Q., CROSSLEY A., CZERNUSZKA J. Preparation and characterization of negatively charged poly (lactic-co-glycolic acid) microspheres. Journal of pharmaceutical sciences, 98, 2009, p.2377-2389.

15. SHAHIN M., HADY S. A., HAMMAD M., MORTADA N. Development of stable O/W emulsions of three different oils. Int J Pharm Stud Res, 2, 2011, p.45-51.

16. TURK C., OZ U., SERIM T., HASCICEK C. Formulation and optimization of nonionic surfactants emulsified nimesulide-loaded PLGA-based nanoparticles by design of experiments. Aaps pharmscitech, 15, 2014, p.161-176.

17. DOS SANTOS O. D., MIOTTO J. V., DE MORAIS J. M., DA ROCHA-FILHO P. A., DE OLIVEIRA W. P. Attainment of emulsions with liquid crystal from marigold oil using the required HLB method. Journal of dispersion science and technology, 26, 2005, p.243-249.

Manuscript received: 29.11 .2019 